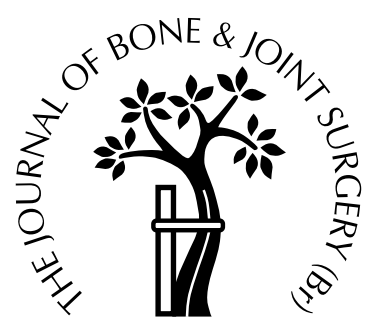

\title{
Conversion of biarticular to monoarticular muscles as a component of multilevel surgery in spastic diplegia
}

\author{
D. Metaxiotis, S. Wolf, L. Doederlein \\ From the University of Heidelberg, Germany
}

W e treated 20 children (40 limbs) with diplegic cerebral palsy who could walk by multilevel soft tissue operative procedures including conversion of the biarticular semitendinosus and gastrocnemius to monoarticular muscles. The mean age at surgery was 11.5 years (5.6 to 17.0). All patients underwent clinical and radiological examination and three-dimensional instrumented gait analysis before and at a mean of 3.1 years $(2.0$ to 4.5$)$ after surgery.

The passive range of movement at the ankle, knee and hip showed improvement at follow-up. Kinematic parameters indicated a reduced pelvic range of movement and improvement of extension of the knee in single stance after operation $(\mathbf{p}<\mathbf{0 . 0 0 0 1})$. However, postoperative back-kneeing was detected in five of the 40 limbs. The kinetic studies showed that the power of the hamstrings and plantar flexors of the ankle was maintained while the maximum knee extensor moment during stance was reduced. The elimination of knee flexor activity of semitendinosus and gastrocnemius combined with transfer of distal rectus femoris led to an improvement in gait as confirmed by gait analysis.

J Bone Joint Surg [Br] 2004;86-B:102-9.

Received 16 July 2002; Accepted after revision 28 April 2003

Patients with cerebral palsy have more difficulty in controlling biarticular than monoarticular muscles because the former demand a high level of motor control. ${ }^{1}$ The biarticular muscles of the lower limbs work under normal conditions as activatable slings. ${ }^{2-3}$ This reduces the overall energy consumption of walking ${ }^{4,5}$ by transferring energy from one

D. Metaxiotis, MD, PhD, Physicist

L. Doederlein, MD, Orthopaedic Surgeon

Department of Orthopaedic Surgery, University of Heidelberg, Schlierbacher Landstrasse 200A, 69118 Heidelberg, Germany.

Correspondence should be sent to Dr D. Metaxiotis.

(C)2004 British Editorial Society of Bone and Joint Surgery doi:10.1302/0301-620X.86B1.13689\$2.00 joint to the other. The co-ordinated linked movement of the joints which they $\operatorname{span}^{6}$ requires a high level of motor control as they change their contraction status which may be eccentric, concentric or isometric. ${ }^{7,8}$

The function of the biarticular muscles in cerebral palsy is characterised by their decreased ability to work as energy transfer straps and to adapt with fine control changes to the demands of eccentric or concentric contraction in quick movements. Gage et $\mathrm{al}^{1}$ stated that the abnormal function of biarticular muscles can be simplified or modified by surgery.

Operations on the biarticular muscles of patients with cerebral palsy who can walk may be divided into two groups. The first includes aponeurotic or z-plasty lengthenings and muscle transfers, ${ }^{9,10}$ which do not change the biarticular character of the muscle. In the second the biarticular muscles are converted to monoarticular muscles. ${ }^{11-13}$ Operative elongation of a muscle can lead to structural changes in the muscle or tendon ${ }^{14}$ and to post-operative muscle weakness. ${ }^{15}$ This can be a disadvantage in the long term because the muscles are already weakened by the cerebral palsy. ${ }^{16}$

Silfverskiöld ${ }^{11}$ converted the gastrocnemius, hamstrings and rectus femoris into monoarticular muscles and later Eggers ${ }^{12}$ transplanted the medial and lateral hamstring tendons to the femoral condyles. Thom ${ }^{13}$ and Döderlein ${ }^{17}$ reported a modification of the methods of Eggers and Silfverskiöld. These methods, however, which involved both the medial and lateral hamstrings, led to insufficiency of the hamstrings and did not address the concomitant extensor spasticity of the knee. ${ }^{18}$ Our aim was to evaluate the effects of converting specific biarticular to monoarticular muscles in children with diplegic cerebral palsy. The changes in the children's gait were assessed by gait analysis.

Patients and Methods

Between March 1996 and July 2001 we carried out a prospective study on 20 patients (40 limbs) with cerebral palsy. Approval had been given by the local Ethics Committee. The inclusion criteria were a spastic diplegic pattern of cerebral palsy, walking with or without aids, the ability to perceive instructions and an age between five and 17 years. The exclusion criteria were an athetotic pattern of cerebral palsy 
Table I. Details of the patients including operations

\begin{tabular}{|c|c|c|c|c|c|c|}
\hline \multirow[b]{2}{*}{ Case } & \multirow{2}{*}{$\begin{array}{l}\text { Age at } \\
\text { op } \\
\text { (yrs) }\end{array}$} & \multirow[b]{2}{*}{ Gender } & \multirow{2}{*}{$\begin{array}{l}\text { Previous lower } \\
\text { limb surgery* }\end{array}$} & \multicolumn{2}{|l|}{ Walking aids } & \multirow[b]{2}{*}{ Surgery $\dagger$} \\
\hline & & & & Pre-op & Post-op & \\
\hline 1 & 7.2 & M & No & No & No & B pRFrel, B dRFtrG, B STtrDF, B GAtrPT, R SPOTT \\
\hline 2 & 14.5 & M & B TAL at 4 yrs & No & No & $\begin{array}{l}\text { B pRFrel, L AddL, B dRFtrG, B STtrDF, B SMimL, B GatrPT, R Bam, L } \\
\text { Steind }\end{array}$ \\
\hline 3 & 11.0 & $\mathrm{~F}$ & No & No & No & B PsOTB, B AddL, B dRFtrG, B STtrDF, B SMimL, B BFimL, B GatrPT \\
\hline 4 & 16.5 & $\mathrm{~F}$ & No & No & Crutches & B pRFrel, B dRFtrG, B STtrDF, B SMimL, B BFimL, B GAtrPT \\
\hline 5 & 9.3 & F & No & No & No & B dRFtrG, B STtrDF, B GAtrPT, R Baum, B SPOTT \\
\hline 6 & 13.4 & M & No & No & No & B pRFrel, B dRFtrG, B STtrDF, B SMimL, B GAtrPT, B FIDO \\
\hline 7 & 13.5 & M & B Add ten at 3 yrs & No & No & B PsOTB, B dRFtrG, B STtrDF, B SMimL, B BFimL, B GAtrPT, B FIDO \\
\hline 8 & 10.9 & M & No & No & No & B pRFrel, B dRFtrG, B STtrDF, B GAtrPT, R FIDO, R TSMDO, R SPOTT \\
\hline 9 & 14.6 & M & B TAL at 9 yrs & Crutches & Crutches & BpRFrel, B dRFtrIT, B STtrDF, B SMzL, B GAtrPT \\
\hline 10 & 8.6 & M & No & No & No & B pRFrel, B dRFtrG, B STtrDF, B SMimL, B GAtrPT, B StrOp \\
\hline 11 & 10.0 & $\mathrm{~F}$ & No & No & No & B pRFrel, B dRFtrG, B STtrDF, B GAtrPT, B Baum, B FIDO \\
\hline 12 & 11.0 & M & $\begin{array}{l}\text { B Add ten, B Vulpius } \\
\text { op at } 9 \text { yrs }\end{array}$ & No & No & B pRFrel, B dRFtrG, B STtrDF, B SMimL, B BfimL, B GAtrPT \\
\hline 13 & 17.0 & M & No & No & No & $\begin{array}{l}\text { B PsOTB, B AddL, B dRFtrG, B STtrDF, B SMimL, B GAtrPT, R FIDO, R } \\
\text { TSMDO, L Evans }\end{array}$ \\
\hline 14 & 10.0 & M & No & Posterior walker & No & B pRFrel, B dRFtrG, B STtrDF, B SMimL, B GAtrPT, B Baum \\
\hline 15 & 13.5 & $\mathrm{~F}$ & No & No & No & $\begin{array}{l}\text { L pRFrel, B dRFtrG, B STtrDF, B GAtrPT, L Baum, R StrOp, R FIDO, R } \\
\text { TPOimL, R Steind, L EvansOp, L KramerOp, R FhIL }\end{array}$ \\
\hline 16 & 12.3 & M & No & No & Crutches & B pRFrel, B dRFtrG, B STtrDF, B SMimL, B GAtrPT, R Pemb.Op, B FIDO \\
\hline 17 & 11.0 & M & No & No & No & $\begin{array}{l}\text { B pRFrel, B PsOTB, R AddL, B dRFtrG, B STtrDF, B SMimL, B BFimL, } \\
\text { B GAtrPT, R Triple, R open hip reduction, R FIDO, L Evans, L dorsFlexL }\end{array}$ \\
\hline 18 & 7.4 & $\mathrm{~F}$ & No & Crutches & No & B pRFrel, B dRFtrG, B STtrDF, B GAtrPT \\
\hline 19 & 15.7 & M & B TAL at 6 years & No & No & L PsOTB, B dRFtrG, B STtrDF, B GAtrPT \\
\hline 20 & 5.6 & $\mathrm{~F}$ & No & No & No & B dRFtrG, B STtrDF, B GAtrPT, B Baum, L TPOimL, R Evans, L Grice \\
\hline
\end{tabular}

* B, bilaterally; TAL, tendo Achilles lengthening; Vulpius, Vulpius gastrocnemius lengthening; Add ten, adductor tenotomy

$\dagger$ AddL, adductor longus lengthening; BFimL, biceps femoris intramuscular lengthening; Baum, Baumann procedure; dorsFlexL, lengthening of the foot dorsiflexors; dRFtrG, distal rectus femoris transfer to gracilis; dRFtrIT, distal rectus femoris transfer to iliotibial band; Evans, Evans calcaneal lengthening osteotomy; FhIL, flexor hallucis longus lengthening; FIDO, femoral intertrochanteric derotational osteotomy; GAtrPT, gastrocnemius transfer to proximal tibia; Grice, Grice subtalar fusion; KramerOp, Kramer procedure for Hallux valgus; Pemb. Op, Pemberton pelvic osteotomy; pRFrel, proximal femoris release; PsOTB, psoas lengthening over the brim; SMimL, semitendinosus intramuscular lengthening; SMzL, semimembranosus z-lengthening; SPOTT, split posterior tibial tendon transfer; Steind, Steindler procedure; STtrDF, semitendinosus transfer to distal femur; StrOP, Strayer procedure; TPOimL, tibialis posterior intramuscular lengthening; Triple, triple pelvic osteotomy; TSMDO, tibial supramalleolar derotational osteotomy

and orthopaedic surgery on a lower limb in the year before the study. There were 13 boys and seven girls. Their mean age at surgery was 11.5 years (5.6 to 17.0 ) Seventeen were independent walkers and three walked with an aid (Table I). Pre-operative assessment. Passive range of movement (ROM) and muscle strength (manual muscle testing, MRC scale 0 to 5) were assessed clinically by one of the authors (DM or LD). Clinical measurements, such as the Thomas test, the measurement of the popliteal angle and the Silfverskiöld test were carried out pre- and post-operatively and additionally under anaesthesia just before surgery.

Radiological examination was used to detect any deformities of the hip and foot. Three-dimensional instrumented gait analysis included videotaping in the frontal and sagittal planes, kinematics with a six-camera $(50 \mathrm{~Hz})$ videobased motion-capturing system (Vicon 370; Oxford Metrics, Oxford, UK) and kinetics with two floor-mounted force plates (Kistler, Winterthur, Switzerland). The patients were instructed to walk at a self-selected speed along a level $7 \mathrm{~m}$ walkway for all tests. All the data were integrated into a custom-made database. A mean of eight consistent cycles was averaged per side and the mean stride analysed. Data collected from a group of ten normal subjects served as a reference base for the interpretation of the results.
Table II. Details of the surgical procedures performed on the 20 patients

\begin{tabular}{lc}
\hline Procedure & Total \\
\hline Psoas lengthening over the brim & 9 \\
Adductor longus lengthening & 6 \\
Proximal rectus femoris release & 27 \\
Medial hamstring lengthening & 26 \\
Lateral hamstring lengthening & 10 \\
Distal semitendinosus transfer & 40 \\
Distal rectus femoris transfer & 40 \\
Proximal gastrocnemius transfer & 40 \\
Intramuscular gastrocnemius transfer & 12 \\
Foot soft-tissue surgery & 9 \\
Other soft-tissue surgery & 2 \\
Pelvic osteotomy & 2 \\
Proximal femur derotation osteotomy & 10 \\
Distal tibia derotation osteotomy & 2 \\
Foot bony surgery & 6 \\
Total soft-tissue procedures & 221 \\
Total bony procedures & 20 \\
Total surgical procedures & 241 \\
Mean procedures per patient & 12.05 \\
\hline
\end{tabular}

Surgery. The surgical procedures (Table II) were performed according to specific criteria based on clinical examination and gait analysis (Table III). All the patients had singlestage, multilevel surgery including soft-tissue and bony 
Table III. Selection criteria for the surgical procedure

\begin{tabular}{|c|c|c|}
\hline Operations & Clinical & Gait analysis \\
\hline Intramuscular psoas lengthening & Fixed hip flexion deformity of $30^{\circ}$ & Inadequate hip extension in stance \\
\hline Proximal rectus femoris release & Duncan-Ely test positive & Pelvic ‘double-bump’ pattern* \\
\hline Distal semitendinosus transfer & Popliteal angle $30^{\circ}$ & Inadequate knee extension in stance \\
\hline Semimembranosus lengthening & Popliteal angle $>40^{\circ}$ & Inadequate knee extension in stance \\
\hline Biceps femoris lengthening & $\begin{array}{l}\text { Severe crouch, intra-operative correction of popliteal } \\
\text { angle after semimembranous lengthening not possible }\end{array}$ & Inadequate knee extension in stance \\
\hline Distal rectus femoris transfer to gracilis & $\begin{array}{l}\text { Duncan-Ely test positive, foot dragging, shoe-wear } \\
\text { pattern }\end{array}$ & Inadequate knee flexion in swing \\
\hline Proximal gastrocnemius transfer to tibia & Silfverskiöld test positive & Increased plantar flexion in stance \\
\hline Gastrocnemius/soleus lengthening & $\begin{array}{l}\text { Intra-operative rest equinus in knee extension after } \\
\text { proximal gastrocnemius transfer }\end{array}$ & Increased plantar flexion in stance \\
\hline Pelvic osteotomy & Hip luxation/subluxation & Hip abductor insufficiency \\
\hline Femoral intertrochanteric osteotomy & $\begin{array}{l}\text { Internal rotation exceeds external rotation by more } \\
\text { than } 30^{\circ} \text { (prone) }\end{array}$ & Hip internal rotation deformity \\
\hline Tibial supramalleolar osteotomy & Tibial external torsion $>15^{\circ}$ & Excessive external rotation of the tibia \\
\hline Foot (bone/soft tissue) & Pes planovalgus, equinovarus & Increased/decreased foot progression angle \\
\hline
\end{tabular}

operations. The mean length of surgery was 3.5 hours (1.6 to 6.0). There were no intra-operative complications.

Operative technique. With the patient prone, a midline longitudinal incision of approximately 6 to $8 \mathrm{~cm}$ was made in the popliteal fossa (Fig. 1a). The tendon of semitendinosous was dissected and released from its insertion. The medial tendinous origin of gastrocnemius was released from the femur leaving a stump of $2 \mathrm{~cm}$ proximally. The lateral head of gastrocnemius was also released from its femoral origin and both heads were sutured to the tibial condyles in order to convert gastrocnemius into a monoarticular muscle. The distal tendon of semitendinosus was sutured to the proximal medial tendinous stump of gastrocnemius (Fig. 1b). The tendon of gracilis was released proximally and prepared for transfer to the distal rectus which was completed with the patient in the supine position (Fig. 1c).

Post-operative management. Epidural anaesthesia was used to manage post-operative pain for the first two to five days. All the patients wore below-knee, weight-bearing casts for four weeks and above-knee, night splints for six

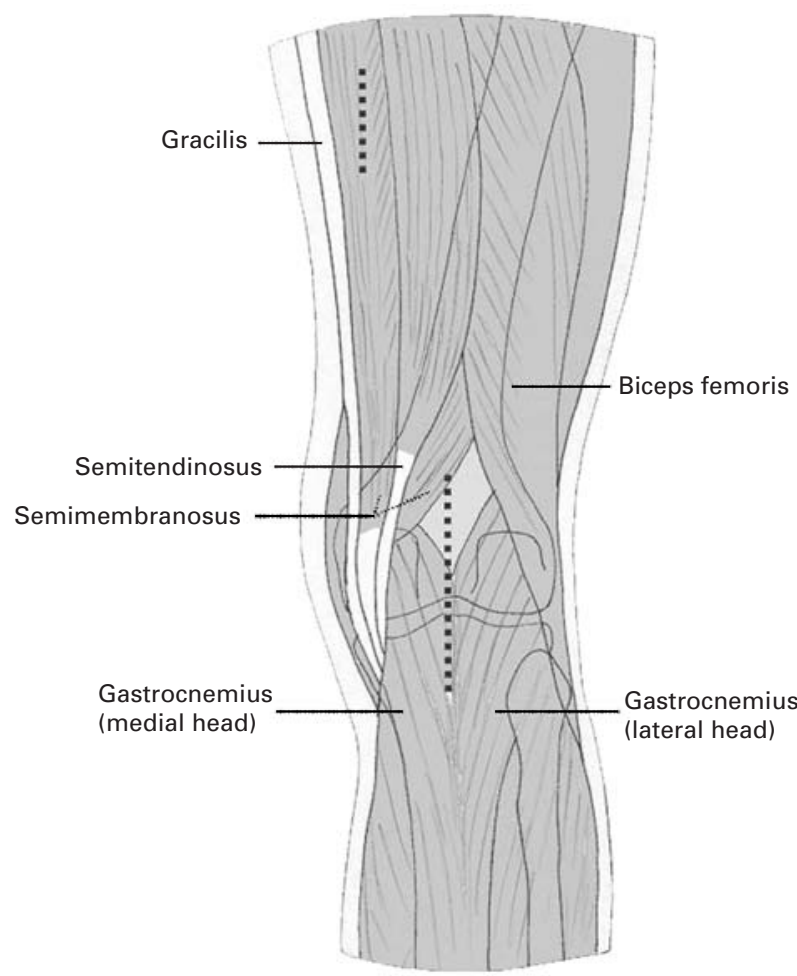

Fig. 1a

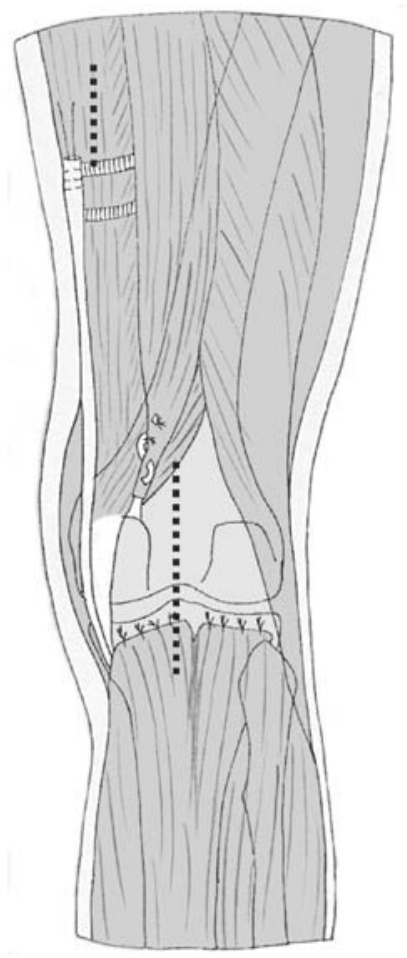

Fig. 1b
Diagrams showing a) the incisions, b) the technique for conversion of semitendinosus and gastrocnemius and c) transfer of distal rectus femoris.

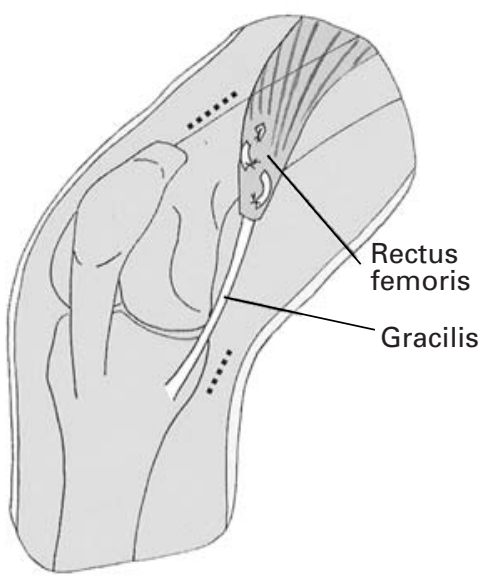

Fig. 1c 
Table IV. Clinical parameters (mean $\pm \mathrm{SD}$ ) evaluated before and after operation

\begin{tabular}{lccc}
\hline Parameter & Pre-op & Post-op & p value \\
\hline Thomas test $\left({ }^{\circ}\right)$ & $12.4 \pm 9.1$ & $3.4 \pm 4.7$ & 0.0000 \\
Popliteal angle $\left({ }^{\circ}\right)$ & $53.6 \pm 13.6$ & $25.00 \pm 12.6$ & 0.0000 \\
Knee flexion power (MRC scale) & $4.0 \pm 0.0$ & $3.1 \pm 0.3$ & 0.0000 \\
Ankle dorsiflexion passive (knee in $\left.90^{\circ}\right)\left({ }^{\circ}\right)$ & $3.8 \pm 8.9$ & $12.3 \pm 7.6$ & 0.0000 \\
Ankle dorsiflexion passive $\left(\mathrm{knee} \mathrm{in} 0^{\circ}\right)\left({ }^{\circ}\right)$ & $-3.8 \pm 9.7$ & $6.5 \pm 6.4$ & 0.0000 \\
Plantar flexion strength (MRC scale) & $3.8 \pm 0.6$ & $3.6 \pm 0.5$ & 0.0385 \\
\hline
\end{tabular}

Table V. Time-distance parameters (mean \pm SD and normalised data) before and after operation.

\begin{tabular}{lccc}
\hline Parameter & Pre-op & Post-op & p value \\
\hline Cadence (steps/min) & $118.26 \pm 25.26$ & $102.50 \pm 23.54$ & 0.0064 \\
Velocity (1/sec)* & $0.59 \pm 0.19$ & $0.58 \pm 0.20$ & 0.6542 \\
Stride length* & $0.60 \pm 0.14$ & $0.67 \pm 0.13$ & 0.0227 \\
Stride time (sec/cm)* & $0.007 \pm 0.00$ & $0.008 \pm 0.00$ & 0.0366 \\
\hline
\end{tabular}

*normalised to body length

Table VI. Kinematic parameters (mean \pm SD) before and after operation

\begin{tabular}{llll}
\hline Parameter & Pre-op & Post-op & p value \\
\hline Pelvic ROM & $8.42 \pm 2.06$ & $6.84 \pm 1.83$ & 0.0009 \\
Max anterior pelvic tilt $\left(^{\circ}\right)$ & $20.18 \pm 3.60$ & $20.00 \pm 6.66$ & 0.9464 \\
Min hip angle stance $\left(^{\circ}\right)$ & $10.11 \pm 13.11$ & $0.85 \pm 8.49$ & 0.0000 \\
Knee angle ROM $\left(^{\circ}\right)$ & $31.86 \pm 15.24$ & $45.23 \pm 13.88$ & 0.0000 \\
Knee ankle angle at initial contact $\left({ }^{\circ}\right)$ & $41.49 \pm 15.43$ & $19.10 \pm 12.780 .0000$ \\
Min knee angle in single stance $\left(^{\circ}\right)$ & $28.67 \pm 23.38$ & $6.23 \pm 14.49$ & 0.0000 \\
Max knee angle in swing $\left({ }^{\circ}\right)$ & $59.29 \pm 12.89$ & $51.44 \pm 8.09$ & 0.0040 \\
Timing of max knee angle in swing $(\%$ of gait cycle) $)$ & $80.63 \pm 6.81$ & $80.65 \pm 4.85$ & 0.7178 \\
Ankle angle ROM $\left(^{\circ}\right)$ & $27.96 \pm 12.08$ & $20.89 \pm 6.06$ & 0.0023 \\
Max ankle angle at initial contact $\left(^{\circ}\right)$ & $-4.53 \pm 20.55$ & $-2.38 \pm 8.87$ & 0.8825 \\
Max ankle angle in single stance $\left(^{\circ}\right)$ & $6.89 \pm 21.91$ & $12.81 \pm 7.70$ & 0.2883 \\
Max ankle angle in swing $\left(^{\circ}\right)$ & $-2.03 \pm 20.36$ & $3.51 \pm 6.20$ & 0.1466 \\
\hline
\end{tabular}

months to maintain extension of the knee. The patients were mobilised early and given a posterior control walker. After four weeks, floor reaction ankle foot orthoses were fitted to assist passive extension of the knee. This was discontinued when the power of gastrocnemius and the hamstrings was sufficient to stabilise the knee in stance. When additional bony surgery had been performed there was a non-weightbearing period of four to six weeks after surgery. The stay in hospital ranged from six to ten weeks during which daily training in gait and posture was undertaken. After discharge, an outpatient programme of physiotherapy was followed and the patients were reviewed at intervals of six months. The only post-operative complication was a case of unilateral transient palsy of the common peroneal nerve in one patient which had recovered completely five months after operation.

Post-operative assessment. Post-operative clinical examination and three-dimensional gait analysis was performed at a mean follow-up of 3.1 years (2.0 to 4.5$)$ after surgery.

Statistical analysis. We compared the pre-operative and follow-up data of clinical examination, kinematic/kinetic measurements and time-distance parameters using the nonparametric Wilcoxon rank test for matched pairs. The level of statistical significance was set at $\mathrm{p}<0.05$.

\section{Results}

Clinical examination. The clinical findings at follow-up (Table IV) showed an improvement of the flexion contracture of the hip from a pre-operative mean of $12.4^{\circ}$ to $3.4^{\circ}$ at follow-up ( $\mathrm{p}<0.0001)$. The popliteal angle improved from a mean of $53.6^{\circ}$ to $25.0^{\circ}(\mathrm{p}<0.0001)$. The power of the knee flexors and ankle plantar flexor muscles was decreased. The mean dorsiflexion of the ankle with the knee extended changed from $-3.8^{\circ}$ to $6.5^{\circ}(\mathrm{p}<0.0001)$ and with the knee flexed to $90^{\circ}$ from $3.8^{\circ}$ to $12.3^{\circ}$ ( $\mathrm{p}<0.0001$ ).

Time-distance parameters. After operation the patients walked with significantly decreased cadence $(\mathrm{p}<0.05)$ and increased stride length and time $(\mathrm{p}<0.05)$ (Table V).

Kinematics. Anterior pelvic tilt remained unchanged after operation, while the pelvic range of movement was significantly reduced $(\mathrm{p}<0.001)$ and extension of the hip in stance phase was improved $(\mathrm{p}<0.0001)$ (Table VI). The kinematics of the knee showed a decrease of maximum flexion in the swing phase $(p<0.01)$ with unchanged timing, an improvement of the knee angle at initial contact $(p<0.0001)$ and an increase in range of movement of the knee $(\mathrm{p}<0.0001)$ (Fig. 2). Extension of the knee in single stance was improved $(p<0.0001)$ but in four patients (five 


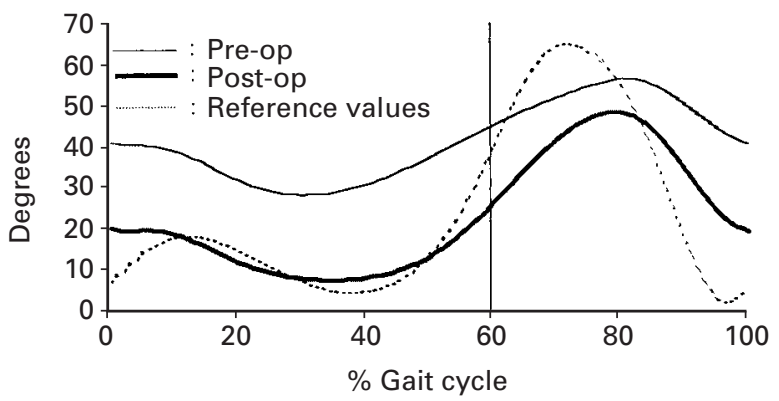

Fig. 2

Graph showing the kinematic changes of the knee (sagittal plane) for all patients before (thin line) and after surgery (thick line). The dotted line indicates the normal values. The vertical line separates the stance from the swing phase.

legs) aged between 7.2 and 11.0 years, an increased extension in single-limb stance (back-kneeing) of $11^{\circ}, 14^{\circ}, 11^{\circ}$, $22^{\circ}$ and $23^{\circ}$, respectively, was noted. Although changes in the ankle angle at the initial contact and during the singlestance and swing phase were not significant, there was a tendency towards improvement.

Kinetics. Pre- and post-operative kinetic measurements were possible in only 11 patients, because of insufficient step length or the use of assistive devices. The hip extensors preserved their maximum hip moment and power in the first double-support phase and in the first half of the stance phase (Table VII). The maximum hip power during the second double-support phase showed a slight but not significant decrease. In the timing of the hip moment crossover (from extensor to flexor) there was a mean decrease of $3 \%$ which was not statistically significant. The maximum knee extensor moment during stance was significantly reduced $(\mathrm{p}<$ 0.001 ) and remained post-operatively within normal levels (Fig. 3). The maximum ankle plantar flexor moment during the first double-support phase was significantly decreased ( $\mathrm{p}$ $<0.05$ ) and the ankle power generation in the second double support (push-off) was slightly increased $(\mathrm{p}<0.05)$.

\section{Discussion}

Our aim was to assess the post-operative results after conversion of the biarticular muscles of the lower limb to monoarticular muscles in children with diplegic cerebral palsy who can walk. Previous operative methods of converting biarticular muscles (rectus femoris, hamstrings, gastrocnemius) have addressed mainly the hamstrings. ${ }^{12,13,17,19-28}$ These procedures can be grouped according to either the muscles converted (hamstrings (medial, lateral, or both), gastrocnemius, rectus femoris) or the site of the conversion (proximal or distal). Post-operative problems such as genu recurvatum, muscle weakness and extensor spasticity have been reported in previous clinical studies. ${ }^{17,19-28}$ The value of clinical examination in cerebral palsy has been questioned because of its static nature, and the lack of repeatability and reliability. ${ }^{29}$ Except for some objections, ${ }^{30,31}$ the use of instrumented gait analysis has become widely accepted for the planning of treatment and assessment in patients with spastic cerebral palsy. ${ }^{32-34}$ To the authors' knowledge, there has been no previous study which has described the outcome of conversion of biarticular to monoarticular muscles using objective and dynamic methods.

Single-stage, multilevel surgery including bony and softtissue procedures in all planes and at all levels has become an established method for the surgical management of cerebral palsy. ${ }^{35,36}$ The conversion of biarticular muscles, such as semitendinosus and gastrocnemius to monoarticular, should be performed as part of an integrated surgical approach and not as an isolated procedure. Careful interpretation of the pre- and post-operative gait analysis is needed to extract the specific effects of this conversion. Aponeurotic lengthenings of semimembranosus (26/40) and in selected cases of biceps femoris (10/40) were added in order to achieve a popliteal angle of $20^{\circ}$ intra-operatively. We excluded conversion of semimembranosus because of its important contribution to the posterior stability of the knee. ${ }^{37}$ In some cases, lengthening of gastrocnemius and soleus fasciae (12/40), in addition to the proximal gastrocnemius transfers, was necessary in order to achieve adequate correction of equinus. Clinically, an improvement in the popliteal angle was noted probably as a result of lengthening of the hamstrings and the conversion of semitendinosus. The operations on gastrocnemius and soleus increased the passive range of dorsiflexion of the ankle.

Post-operative muscle weakness has been reported after conversion $^{20,25}$ of biarticular muscles. The clinical results of our study demonstrate a decrease in muscle strength of

Table VII. Kinetic parameters (mean \pm SD) in 11 patients only (see text).

\begin{tabular}{lccc}
\hline Parameter & Pre-op & Post-op & p value \\
\hline Max hip extensor moment in first half of stance $(\mathrm{Nm} / \mathrm{kg})$ & $1.11 \pm 0.37$ & $1.12 \pm 0.44$ & 0.9612 \\
Max hip extensor power in first half of stance $(\mathrm{W} / \mathrm{kg})$ & $1.24 \pm 0.46$ & $1.10 \pm 0.99$ & 0.0824 \\
Max hip extensor moment in first double support $(\mathrm{Nm} / \mathrm{kg})$ & $1.10 \pm 0.39$ & $1.12 \pm 0.44$ & 0.9612 \\
Max hip extensor power in first double support $(\mathrm{W} / \mathrm{kg})$ & $0.98 \pm 0.46$ & $0.97 \pm 0.70$ & 0.4852 \\
Max hip power in preswing $(\mathrm{W} / \mathrm{kg})$ & $0.70 \pm 0.59$ & $0.55 \pm 0.34$ & 0.2491 \\
Timing of hip crossover moment $(\%$ of gait cycle) & $35.77 \pm 5.38$ & $32.9 \pm 5.49$ & 0.0646 \\
Max knee extensor moment in stance $(\mathrm{Nm} / \mathrm{kg})$ & $0.80 \pm 0.34$ & $0.39 \pm 0.23$ & 0.0003 \\
Max ankle moment first double support $(\mathrm{Nm} / \mathrm{kg})$ & $0.97 \pm 0.54$ & $0.65 \pm 0.29$ & 0.0061 \\
Max angle power second double support $(\mathrm{W} / \mathrm{kg})$ & $0.96 \pm 0.71$ & $1.19 \pm 0.61$ & 0.0455 \\
\hline
\end{tabular}



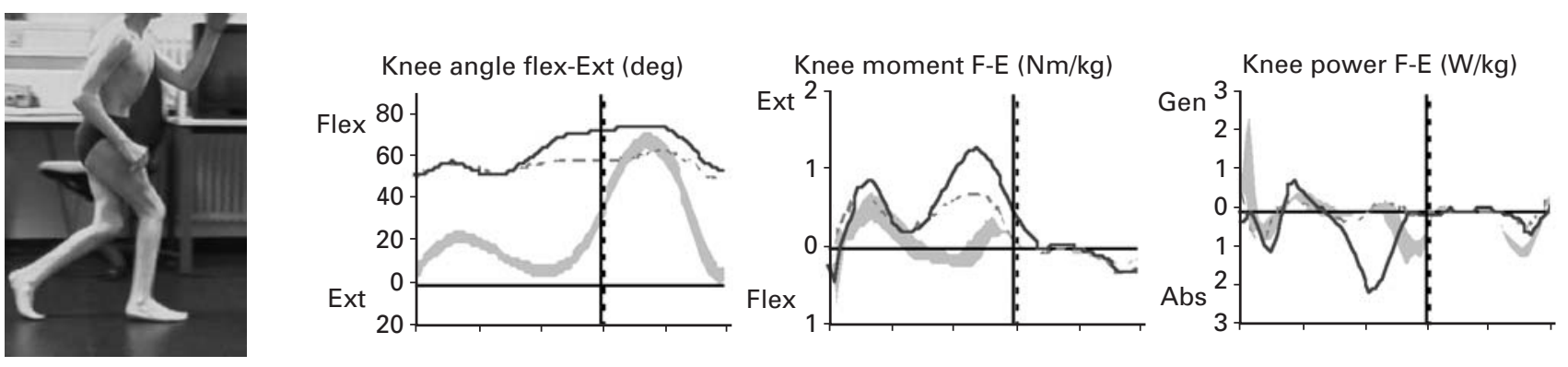

Fig. 3a
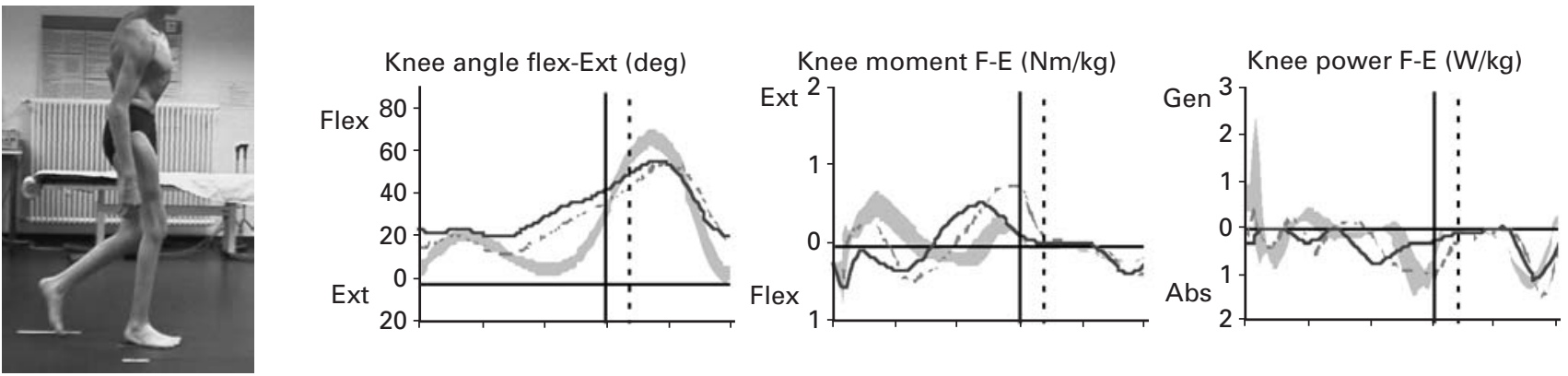

_- Right side
--- Left side
Reference values

Fig. 3b

Example of an 11-year-old patient a) before and b) 25 months after operation with corresponding knee kinematics (left column), moments (middle column) and power (right column). There is an improvement in kinematics and kinetics after surgery.

the hamstrings and ankle plantar flexors, which could not be identified in the kinetic results. Although moments and powers have been used in assessing the post-operative outcome in combination with clinical examination, ${ }^{38}$ they do not always correlate with muscle strength. ${ }^{39}$ It appears that the decrease in muscle strength seen in our patients did not have an adverse effect on parameters of gait.

DeLuca et $\mathrm{al}^{9}$ found that lengthening of the medial and lateral hamstrings led to increased anterior pelvic tilt in patients with a normal pre-operative tilt. Zwick et $\mathrm{al}^{38}$ noticed a slight increase in anterior pelvic tilt after intramuscular lengthening of the medial and lateral hamstrings in $17 \%$ of their cases. We noticed no change in anterior pelvic tilt after surgery, although in ten of the 40 limbs, intramuscular lengthening of the lateral hamstrings was performed. The decrease in the pelvic range of movement in the sagittal plane indicated a post-operative reduction of the pelvic 'double-bump' pattern. Lengthening of psoas over the brim was performed in nine limbs with a flexion contracture of the hip and was aimed at preserving the power of psoas. ${ }^{40,41}$ The reduction of crouch corrected the positional lever-arm dysfunction ${ }^{42}$ of the medial hamstrings and contributed to the improvement of hip extension in stance.
Genu recurvatum after conversion of the hamstrings has been reported by several authors. ${ }^{17,24,27}$ In our study, although no recurvatum was demonstrated on clinical examination, increased knee extension (back-kneeing) during stance was detected by gait analysis in five knees (four patients). In three mild cases the reason was probably slight persistent equinus which exaggerated the plantar flexionknee extension couple. In the more severe case, in a patient with a pre-operative recurvatum and post-operative bilateral back-kneeing $\left(22^{\circ}\right.$ and $\left.23^{\circ}\right)$, no orthotic devices were considered to be necessary because there was sufficient stability of the knee and no problems with unlocking in the terminal stance. In the patient with bilateral involvement, although the hamstring-lengthenings were considered to be necessary intra-operatively, as there was no correction of the popliteal angle after conversion of semitendinosus and lengthening of semimembranosus, back-kneeing could have been avoided if biceps femoris had not been lengthened.

Sutherland et $\mathrm{al}^{18}$ reported an increase in peak flexion of the knee in swing after transfer of the distal rectus. Õunpuu et $\mathrm{al}^{43}$ and Zwick et $\mathrm{al}^{38}$ showed that maximum knee flexion during swing was maintained after transfer of rectus femoris. We noticed a significant reduction of the maximum knee 
flexion in swing which was probably due to simultaneous proximal release in 27 limbs. In these cases rectus femoris was converted to a monoarticular muscle in order to reduce its contribution to the flexor spasticity of the hip and the post-operative risk of anterior pelvic tilt. Nevertheless, the post-operative pattern of the average knee kinematics indicates an improvement of the knee excursion towards normal (Fig. 2). The improvement of the angle at initial contact, extension in stance and range of movement of the knee indicate the reduction of crouch. Similar improvements in kinematics after lengthening of the hamstrings have been demonstrated by other authors. ${ }^{44}$

The mean persistent post-operative equinus at initial contact was $2^{\circ}$ which could be considered to be of limited clinical significance. The maximum dorsiflexion in single stance and swing showed improvement. Both findings correlated with previous studies ${ }^{45,46}$ and contributed to the improvement of stability in stance and foot clearance in swing.

The normalisation of the time distance parameters to height was considered to be necessary since the patients grew $5.6 \mathrm{~cm}$ on average during the mean follow-up time of 3.1 years. Although we did not include any measurements of oxygen consumption, the post-operative decrease in cadence could indicate a lower energy consumption as shown by Abel and Damiano. ${ }^{47}$

Ounpuu et $\mathrm{al}^{48}$ have pointed out that the interpretation of the kinetic results should emphasise their patterns and timing. Release of proximal rectus femoris in 27 limbs and intramuscular lengthening of psoas in nine did not seem to affect the ability of the hip flexors to generate power during the preswing. The importance of the propulsive function of the hamstring muscles has been already emphasised. ${ }^{49} \mathrm{We}$ found no signs of insufficiency of the hamstrings in the post-operative kinetic results. The extensor moment and the power generation of the hip during the first half of stance remained unchanged. The knee extension moment during stance was reduced due to the correction of crouch gait.

The ankle plantar flexor moment at loading response was reduced after operation indicating a reduction of the spastic reaction of the calf muscles during transfer of weight. A significant increase in positive work for push-off after intramuscular lengthening of triceps surae has been reported by Rose et $\mathrm{al}^{45}$ and Saraph et al. ${ }^{46}$ In our patients gastrocnemius, despite its exclusion from knee flexion, increased its maximum power which contributed to propulsion during push-off.

Winter ${ }^{50}$ suggested that ankle power is transferred above the knee through rectus femoris, but Lieber ${ }^{51}$ postulated that semitendinosus works as an activatable sling and links the monoarticular knee extensors with the knee. Van Ingen Schenau $^{2}$ suggested that gastrocnemius facilitiates the transfer of energy from the knee to the ankle. Our results indicate that excluding semitendinosus and gastrocnemius from crossing the knee did not affect their propulsive power during walking. According to Waters et al, ${ }^{49}$ the hamstrings contribute approximately one-third of the extensor power of the hip in a normal subject. A conventional way of expressing a muscle's force-generating capacity is in terms of its physiological cross-sectional area (PSCA). ${ }^{52}$ Friederich and Brand $^{53}$ found in a cadaver study that semitendinosus constitutes $22 \%$ of the total hamstring PCSA. From the kinematic and kinetic results, we could not estimate accurately the contribution made by conversion of semitendinosus and gastrocnemius. Our findings suggest, however, that the dynamic coupling between the knee and ankle is not interrupted by the conversion of semitendinosus and gastrocnemius to monoarticular muscles. Despite its limitation, ${ }^{54}$ computer modelling may provide an additional insight into the function of the converted biarticular muscles.

Bell et $\mathrm{al}^{55}$ and Johnson, Damiano and $\mathrm{Abel}^{56}$ have documented a decline in gait function with growth in children with cerebral palsy using gait analysis. In our study the variation in follow-up time (2.0 to 4.5 years) makes it impossible to assess the effects of growth, but could indirectly provide information about the tendency to recurrence of dysfunction of gait. Therefore, both the unknown impact of growth and the risk of recurrence after multilevel surgery should be investigated in the long-term results of further prospective, controlled studies.

We wish to thank Dr Freeman Miller for his help in preparing the manuscript and the Leopold Klinge Foundation for the project grant supporting this work.

No benefits in any form have been received or will be received from a commercial party related directly or indirectly to the subject of this article.

\section{References}

1. Gage JR, DeLuca PA, Renshaw TS. Gait analysis: principles and applications with emphasis on its use in cerebral palsy. Instr Course Lect 1996;45:491-507.

2. van Ingen Schenau GJ. From rotation to translation: constraints on multi-joint movements and the unique action of bi-articular muscles. Human Movement Science 1989;8:301-37.

3. Prilutsky BI, Zatsiorsky VM. Tendon action of two-joint muscles: transfer of mechanical energy between joints during jumping, landing and running. J Biomech 1994;27:25-34.

4. Prilutsky BI, Petrova LN, Raitsin LM. Comparison of mechanical energy expenditure of joint moments and muscle forces during human locomotion. J Biomech 1996;29:405-15.

5. Wells RP. Mechanical energy costs of human movement: an approach to evaluating the transfer possibilities of two-joint muscles. J Biomech 1998;21:955-64.

6. Prilutsky BI. Coordination of two- and one-joint muscles: functional consequences and implications for motor control. Motor Control 2000; $4: 1-44$.

7. Lieber RL. Hypothesis: biarticular muscles transfer moments between joints. Dev Med Child Neurol 1990;32:456-8.

8. Markee JE, Jogue JT, Williams M, et al. Two-joint muscles of the thigh. J Bone Joint Surg [Am] 1955;37-A:125-42.

9. DeLuca PA, Ounpuu S, Davis RB, Walsh JH. Effect of hamstring and psoas lengthening on pelvic tilt in patients with spastic diplegic cerebral palsy. J Pediatr Orthop 1998;18:712-8.

10. Gage JR, Perry J, Hicks RR, Koop S, Werntz JR. Rectus femoris transfer to improve knee function of children with cerebral palsy. Dev Med Child Neurol 1987;29:159-66.

11. Silfverskiöld N. Reduction of the uncrossed two-joint muscles of the leg to one-joint muscles in spastic conditions. Acta Chirurg Scan 1924;56:315-30.

12. Eggers GWN. Transplantation of hamstring tendons to femoral condyles in order to improve hip extension and to decrease knee flexion in cerebral spastic paralysis. J Bone Joint Surg [Am] 1952;34-A $827-30$ 
13. Thom H. Zur operativen Behandlung von Kniebeugekontrakturen. Z Orthop 1972;101:630-40.

14. Jozsa L, Kannus P, Thoring J, et al. The effect of tenotomy and immobilisation on intramuscular connective tissue: a morphometric and microscopic study in rat calf muscles. J Bone Joint Surg [Br] 1990; 72-B:293-7.

15. Brunner R. Changes in muscle power following tendon lengthening and tendon transfer. Orthopäde 1995;24:246-51.

16. Wiley ME, Damiano DL. Lower-extremity strength profiles in spastic cerebral palsy. Dev Med Child Neurol 1998 Feb;40:100-7.

17. Döderlein L. Ergebnisse de Kniebeugesehnenoperationen nach Thom. Orthop Praxis 1986;7:526-30.

18. Sutherland DH, Santi M, Abel MF. Treatment of stiff knee gait in cerebral palsy: a comparison by gait analysis of distal rectus femoris transfer versus proximal rectus release. J Pediatr Orthop 1990;10: 433-41.

19. Bertrand P. Correction du genu flexum chez les spastiques. Rev Chir Orthop 1959;45:416-23.

20. Keats S, Kambin P. An evaluation of surgery for the correction of kneeflexion contracture in children with cerebral paralysis. J Bone Joint Surg [Am] 1962;44-A:1146-54.

21. Evans EB, Julian JD. Modifications of the hamstring transfer. Dev Med Child Neurol 1966;8:539-51.

22. Pollock GA, English TA. Transplantation of the hamstring muscles in cerebral palsy. J Bone Joint Surg [Br] 1967;49-B:80-6.

23. Seymour N, Sharrard WJ. Bilateral proximal release of the hamstrings in cerebral palsy. J Bone Joint Surg [Br] 1968;50-B:274-7.

24. Drummond DS, Rogala E, Templeton J, Cruess R. Proximal hamstring release for knee flexion and crouched posture in cerebral palsy. J Bone Joint Surg [Am] 1974;56-A:1598-602.

25. Reimers J. Contracture of the hamstrings in spastic cerebral palsy: a study of three methods of operative correction. J Bone Joint Surg [Br] 1974;56-B:102-9.

26. Papadimitriou GN, Petropoulos AB. Ergebnisse der operativen Behandlung von Kniebeugekontrakturen beim Spastiker nach der Methode Eggers/Thom (Modifikation II). Orthop Praxis 1979;9:778-82.

27. Sharps CH, Clancy M, Steel HH. A long-term retrospective study of proximal hamstring release for hamstring contracture in cerebral palsy. J Pediatr Orthop 1984;4:443-7.

28. Damron T, Breed AL, Roecker E. Hamstring tenotomies in cerebral palsy: long-term retrospective analysis. J Pediatr Orthop 1991;11: 514-9.

29. McDowell BC, Hewitt V, Nurse A, Weston T, Baker R. The variability of goniometric measurements in ambulatory children with spastic cerebral palsy. Gait Posture 2000;12:114-21.

30. Morton R. New surgical inverventions for cerebral palsy and the place of gait analysis. Dev Med Child Neurol 1999;41:424-8.

31. Watts HG. Gait laboratory analysis for preoperative decision making in spastic cerebral palsy: is it all it's cracked up to be? J Pediatr Orthop 1994;14:703-4.

32. Gage JR. The role of gait analysis in the treatment of cerebral palsy. J Pediatr Orthop 1994;14:701-2.

33. DeLuca PA, Davis RB 3rd, Ounpuu S, Rose S, Sirkin R. Alterations in surgical decision making in patients with cerebral palsy based on three-dimensional gait analysis. J Pediatr Orthop 1997;17:608-14.

34. Kay RM, Dennis S, Rethlefsen S, Skaggs DL, Tolo VT. Impact of postoperative gait analysis on orthopaedic care. Clin Orthop 2000;374:259-64.
35. Norlin R, Tkaczuk H. One session surgery on the lower limb in children with cerebral palsy: a five year follow-up. Int Orthop 1992;16: 291-3.

36. Nene AV, Evans GA, Patrick JH. Simultaneous multiple operations for spastic diplegia: outcome and functional assessment of walking in 18 patients. J Bone Joint Surg [Br] 1993;75-B:488-94.

37. von Lanz T, Wachsmuth W. Praktische anatomie. Berlin: Springer Verlag, 1972;190-214.

38. Zwick EB, Saraph V, Linhart WE, Steinwender G. Propulsive function during gait in diplegic children: evaluation after surgery for gait improvement. J Pediatr Orthop Br 2001;10:226-33.

39. Gage JR. The clinical use of kinetics for evaluation of pathological gait in cerebral palsy. Instr Course Lect 1995;44:507-15.

40. Sutherland DH, Zilberfarb JL, Kaufman KR, Wyatt MP, Chambers HG. Psoas release at the pelvic brim in ambulatory patients with cerebral palsy: operative technique and functional outcome. J Pediatr Orthop 1997;17:563-70.

41. Novatchek TF, Trost JP, Schwartz MH. Intramuscular psoas lengthening improves hip function in children with cerebral palsy. Gait Posture 2001;14:121-2.

42. Gage JR, Novacheck TF. An update on the treatment of gait problems in cerebral palsy. J Pediatr Orthop B 2001;10:265-74.

43. Ounpuu S, Muik E, Davis RB 3rd, Gage JR, DeLuca PA. Rectus femoris surgery in children with cerebral palsy. Part II: A comparison between the effect of transfer and release of the distal rectus femoris on knee motion. J Pediatr Orthop 1993;13:331-5.

44. Steinwender G, Saraph V, Zwick EB, Uitz C, Linhart W. Assessment of gait improvement surgery in diplegic children using computerised gait analysis. Acta Chir Austriaca 2000;32:237-41.

45. Rose SA, DeLuca PA, Davis RB 3rd, Ounpuu S, Gage JR. Kinematic and kinetic evaluation of the ankle after lengthening of the gastrocnemius fascia in children with cerebral palsy. $J$ Pediatr Orthop 1993; 13:727-32.

46. Saraph V, Zwick EB, Uitz C, Linhart W, Steinwender G. The Baumann procedure for fixed contracture of the gastrosoleus in cerebral palsy: evaluation of function of the ankle after multilevel surgery. J Bone Joint Surg [Br] 2000;82-B:535-40.

47. Abel MF, Damiano DL. Strategies for increasing walking speed in diplegic cerebral palsy. J Pediatr Orthop 1996;16:753-8.

48. Ounpuu S, Gage JR, Davis RB. Three-dimensional lower extremity joint kinetics in normal pediatric gait. J Pediatr Orthop 1991;11:341-9.

49. Waters RL, Perry J, McDaniels JM, House K. The relative strength of the hamstrings during hip extension. J Bone Joint Surg [Am] 1974;56-A:1592-7.

50. Winter DA. Energy generation and absorption at the ankle and knee during fast, natural and slow cadences. Clin Orthop 1983;175:147-54.

51. Lieber RL. Skeletal muscle structure and function. Baltimore: Williams and Wilkins, 1992:111-58.

52. Brand RA, Pedersen DR, Friederich JA. The sensitivity of muscle force predictions to changes in physiologic cross-sectional area. J Biomech 1986;19:589-96.

53. Friederich JA, Brand RA. Muscle fiber architecture in the human lower limb. J Biomech 1990;23:91-5.

54. Delp SL, Statler K, Carroll NC. Preserving plantar flexion strength after surgical treatment for contracture of the triceps surae: a computer simulation study. J Orthop Res 1995;13:96-104.

55. Bell KJ, Ounpuu S, DeLuca PA, Romness MJ. Natural progression of gait in children with cerebral palsy. J Pediatr Orthop 2002;22:677-82.

56. Johnson DC, Damiano DL, Abel MF. The evolution of gait in children and adolescent cerebral palsy. J Pediatr Orthop 1997;17:392-6. 